\title{
The main actors involved in parasitization of Heliothis virescens larva
}

\author{
Annalisa Grimaldi • Gianluca Tettamanti • \\ Terenzio Congiu • Rossana Girardello • \\ Davide Malagoli • Patrizia Falabella • \\ Roberto Valvassori • Enzo Ottaviani • \\ Magda de Eguileor
}

Received: 20 March 2012 / Accepted: 12 September 2012

(C) Springer-Verlag Berlin Heidelberg 2012

\begin{abstract}
At the moment of parasitization by another insect, the host Heliothis larva is able to defend itself by the activation of humoral and cellular defenses characterized by unusual reactions of hemocytes in response to external stimuli. Here, we have combined light and electron microscopy, staining reactions, and immunocytochemical characterization to analyze the activation and deactivation of one of the most important immune responses involved in invertebrates defense, i.e., melanin production and deposition. The insect host/parasitoid system is a good model to study these events. The activated
\end{abstract}

This work was supported by Fondi di Ateneo per la Ricerca (FAR) and Centro Grandi Attrezzature (CGA) of the University of Insubria.

A. Grimaldi $(\bowtie) \cdot$ G. Tettamanti $\cdot$ R. Girardello $\cdot$ R. Valvassori

M. de Eguileor

Department of Biotechnology and Life Sciences,

University of Insubria,

Via J. H. Dunant 3,

21100 Varese, Italy

e-mail: annalisa.grimaldi@uninsubria.it

T. Congiu

Department of Surgical and Morphological Science,

University of Insubria,

Via Monte Generoso 3,

21100 Varese, Italy

P. Falabella

Dipartimento di Biologia, Difesa e Biotecnologie Agro-Forestali,

University of Basilicata,

Via dell'Ateneo Lucano 10,

85100 Potenza, Italy

D. Malagoli $\cdot$ E. Ottaviani

Department of Life Science,

University of Modena and Reggio Emilia,

Via Campi 213/D,

41125 Modena, Italy granulocytes of the host insect are a major repository of amyloid fibrils forming a lattice in the cell. Subsequently, the exocytosed amyloid lattice constitutes the template for melanin deposition in the hemocel. Furthermore, cross-talk between immune and neuroendocrine systems mediated by hormones, cytokines, and neuromodulators with the activation of stress-sensoring circuits to produce and release molecules such as adrenocorticotropin hormone, alpha melanocytestimulating hormone, and neutral endopeptidase occurs. Thus, parasitization promotes massive morphological and physiological modifications in the host insect hemocytes and mimics general stress conditions in which phenomena such as amyloid fibril formation, melanin polymerization, proinflammatory cytokine production, and activation of the adrenocorticotropin hormone system occur. These events observed in invertebrates are also reported in the literature for vertebrates, suggesting that this network of mechanisms and responses is maintained throughout evolution.

Keywords Hemocytes - Stress responses - Amyloid fibrils · ACTH axis $\cdot$ Heliothis virescens (Insecta)

$\begin{array}{ll}\text { Abbreviations } \\ \text { AcPase } & \text { Acid phosphatase } \\ \text { ACTH } & \text { Adrenocorticotropin hormone } \\ \alpha \text {-MSH } & \text { Alpha melanocyte-stimulating hormone } \\ \text { IL-18 } & \text { Interleukin } 18 \\ \text { NAC } & \text { N-acetyl cysteine } \\ \text { NEP } & \text { Neutral endopeptidase } \\ \text { PASM } & \text { Periodic acid-silver methenamine stain } \\ \text { PG } & \text { Proteoglycans } \\ \text { PhO } & \text { Phosphoramidon } \\ \text { pro-PO } & \text { Pro-phenoloxidase } \\ \text { ROS } & \text { Reactive oxygen species }\end{array}$




\section{Introduction}

Insects are well known as being able to recognize and fight parasites by utilizing humoral and cellular defenses. In host/ parasitoid systems, endophagous parasitoids, simultaneously with the injection of eggs, overcome host defenses through the maternal fluids (venom, calyx fluid with or without polydnaviruses, and ovarian proteins). Toxoneuron nigriceps (Hymenoptera) is a parasitoid of the larval stages of the tobacco budworm Heliothis virescens (Lepidoptera) in which the precocious alterations induced by the parasitoid factors rapidly provoke severe impairment of immune and neuroendocrine systems (Gupta 1985; Lawrence and Lanzrein 1993; Hillyer and Christensen 2002; Whitfield and Asgari 2003; Ferrarese et al. 2005; Pennacchio and Strand 2006; Ribeiro and Brehelin 2006; Zheng et al. 2006). In $H$. virescens larva, following T. nigriceps oviposition, an elaborate interrelationship between host immune responses and parasitoid maternal secretions takes place (Ratcliffe et al. 1985; Lavine and Strand 2002; Falleiros et al. 2003; Ferrarese et al. 2005; Castillo et al. 2006). One of the effects of parasitism on host hemocytes results in the production of amyloid fibrils that, in turn, promote melanin synthesis (Falabella et al. 2012).

In physiological events associated with melanosomal maturation (Wolff and Schreiner 1971; Diment et al. 1995; Slominski et al. 2005; Cotter 2007; Fowler et al. 2006) or in pathological states such as Alzheimer's disease (AD; Christen 2000; Squier 2001; Drake et al. 2003; Swerdlow and Khan 2004; Zhu et al. 2004; Chen et al. 2005; Wang et al. 2006; Greenwald and Riek 2010), several concomitant events occur that support both amyloid fibril formation and melanin synthesis. On the basis of these observations, we report here the major morpho-functional alterations in host hemocytes, with particular attention being given to amyloid and melanin deposition.

Extensive studies of basal eumetazoans and vertebrates have demonstrated that hemocytes possess a conserved common pool of molecules similar to classical mediators of mammalian stress responses, such as pro-inflammatory cytokines, biogenic amines, adrenocorticotropin hormone (ACTH), and alpha melanocyte-stimulating hormone ( $\alpha$-MSH), able to mediate the activities of immune and neuroendocrine systems. The existence of physiological roles of ACTH in neuroendocrine and immune functions (Verhaert et al. 1984; Genedani et al. 1994; Ottaviani and Franceschi 1997; Ottaviani et al. 1997, 2007) and the correlation among ACTH, stress responses, and melanotic capsule formation (Smith et al. 1991; Scharrer and Stefano 1994; Scharrer et al. 1996; Franchini et al. 1996; Bidla et al. 2005; Loof et al. 2011), on the one hand, and parasitization considered as "external stimuli", on the other, have allowed us to examine the possible relationship between the activated hemocyte, amyloid/melanin production, and the massive synthesis of molecules linked to the stress response, such as ACTH, neutral endopeptidase (NEP), $\alpha$-MSH, and correlated cytokines (Ottaviani and Franceschi 1997; Ottaviani et al. 1997, 2007).

\section{Materials and methods}

Hemocyte extraction and culture

Heliothis virescens hemocytes were obtained from last instar larvae at $2 \mathrm{~h}$ after parasitization by Toxoneuron nigriceps and from synchronous nonparasitized controls. The larval body surfaces were cleaned with $70 \%$ ethanol and bled into ice-cold MEAD solution $(98 \mathrm{mM} \mathrm{NaOH}, 145 \mathrm{mM} \mathrm{NaCl}$, $17 \mathrm{mM}$ EDTA, $41 \mathrm{mM}$ citric acid, $\mathrm{pH} 4,5$ ) by removing the first pair of legs. Samples of hemolymph $(40 / 60 \mu$ per larva) were collected and transferred into Eppendorf tubes containing an equal volume of the buffer MEAD. Hemocytes were pelletted by centrifugation of the hemolymph at $400 \mathrm{~g}$ for $7 \mathrm{~min}$ at $4^{\circ} \mathrm{C}$, resuspended in complete medium (Grace's medium, 10\% fetal bovine serum, 1\% antibiotic-antimicotic solution [Sigma]), and plated at $1 \times 10^{6}$ cells $/ \mathrm{ml}$ in $24-w e l l$ culture plates.

Light microscopy and transmission and scanning electron microscopy

$H$. virescens hemocytes were collected as previously described. For routine transmission electron microscopy (TEM), cells were fixed at $4^{\circ} \mathrm{C}$ for $2 \mathrm{~h}$ in $2 \%$ glutaraldehyde in $0.1 \mathrm{M} \mathrm{Na}$-cacodylate buffer ( $\mathrm{pH}$ 7.2). Pellets were washed in $0.1 \mathrm{M} \mathrm{Na}$-cacodylate buffer (pH 7.2) and postfixed at $4^{\circ} \mathrm{C}$ for $2 \mathrm{~h}$ with $1 \%$ osmic acid in cacodylate buffer $(\mathrm{pH}$ 7.2). After standard dehydration in an ethanol series, samples were embedded in an Epon-Araldite 812 mixture and sectioned with a Reichert Ultracut S ultratome (Leica, Nussloch, Germany). Semithin sections were stained by conventional methods (crystal violet and basic fuchsin, May-Grünwald Giemsa) and were observed with a light microscope (Olympus, Tokyo, Japan). Thin sections were stained by uranyl acetate and lead citrate and observed with a Jeol 1010 electron microscope (Jeol, Tokyo, Japan). Samples for scanning electron microscopy (SEM) were prepared by standard procedures.

Amyloid fibril characterization

Amyloid structures were identified according to Le Vine (1999) by staining cells with thioflavine T and visualizing the amyloid-specific green/yellow fluorescence with an Olympus $\mathrm{BH} 2$ microscope. Images were acquired with a DS-5 M-L1 Nikon digital camera system. Furthermore, in 
order to complete the characterization of the amyloid fibrillar structure in which the major component is fibrillar protein (Falabella et al. 2012), selective staining was utilized to characterize the associated minor constituents such as proteoglycans.

\section{- Safranin staining for proteoglycans}

For the light-microscopy approach, we used semithin sections stained with safranin solution, which selectively binds proteoglycans (deep reddish tinge; Camplejohn and Allard 1988).

- Alcian Blue staining for proteoglycans

Samples were processed according to Ruggeri et al. (1975). Briefly, the specimens were fixed for $2 \mathrm{~h}$ at $4^{\circ} \mathrm{C}$ in 3\% glutaraldehyde in $0.1 \mathrm{M}$ phosphate-buffered saline (PBS), $\mathrm{pH}$ 7.4. After a pre-incubation for $1 \mathrm{~h}$ at room temperature in $25 \mathrm{mM}$ acetate buffer, $\mathrm{pH} 5.8$, containing $\mathrm{MgCl}_{2}$ at the same concentration used in the subsequent staining solution, samples were incubated in the staining solution $(0.05 \% \mathrm{w} / \mathrm{v}$ Alcian Blue $8 \mathrm{GX}$ in $25 \mathrm{mM}$ acetate buffer and $\mathrm{MgCl}_{2}$ at final concentrations of $0.05 \mathrm{M}, 0.3 \mathrm{M}, 0.8 \mathrm{M}, 1 \mathrm{M}, 1.2 \mathrm{M}$ ) for $7 \mathrm{~h}$. After being rinsed for $1 \mathrm{~h}$ in $\mathrm{MgCl}_{2}$-acetate buffer, specimens were placed first in $0.01 \mathrm{~N} \mathrm{HCl}$ for $4 \mathrm{~h}$, then in distilled water for $1 \mathrm{~h}$, and finally in PBS for $30 \mathrm{~min}$. Dehydration in an ethanol series preceded inclusion in Epon resin. Thin sections were stained and observed as previously specified.

Intracellular reactive oxygen species evaluation

Oxidative stress can induce proteins to adopt an insoluble beta-pleated sheet conformation (Drake et al. 2003), and according to numerous authors (Christen 2000; Squier 2001; Zhu et al. 2004; Chen et al. 2005; Du and Yan 2010), oxidative damage appears to be the earliest events preceding amyloid fibril formation. Thus, it is important to measure the host hemocyte overproduction of reactive oxygen species (ROS) in relation to parasitoid egg injection, when circulating cells come into contact with the parasite maternal fluid responsible for amyloid fibril production (Falabella et al. 2012). A gross-identification of cells showing increased ROS production is obtained with differential May-Grünwald Giemsa staining depending on the cytoplasmic $\mathrm{pH}$ (alkaline $\mathrm{pH}$ increases the blue tinge and acid $\mathrm{pH}$ the pink or reddish tinge in the stained specimens). In addition ROS production was validated by use of $2^{\prime}, 7^{\prime}$-dichlorodihydrofluorescein diacetate $\left(\mathrm{H}_{2}\right.$ DCFDA; Molecular Probes, Eugene, Ore., USA), a fluorigenic probe commonly used to detect the overall degree of intracellular level of ROS. $\mathrm{H}_{2}$ DCFDA is a non-fluorescent compound that readily crosses cell membranes. It is hydrolyzed to $2^{\prime}, 7^{\prime}$-dichlorofluorescein (DCF) within cells and becomes fluorescent when it is oxidized by ROS. Oxidation can be detected by monitoring the increase in fluorescence. Fluorescence of the oxidized dye is determined at $525 \mathrm{~nm}$ emission. According to manufacturer's protocol, control and activated hemocytes (host parasitized hemocytes) were washed once in fresh medium, re-suspended in PBS, and incubated in the dark with $10 \mu \mathrm{M} \mathrm{H} \mathrm{H}_{2}$ DCFDA for $30 \mathrm{~min}$ at room temperature. Fluorescence was determined by excitation at $488 \mathrm{~nm}$ and emission at wave lengths of $530 \pm 15 \mathrm{~nm}$. Fluorescent images visualized on a fluorescence microscope (Olympus BH2) were acquired with a DS-5 M-L1 Nikon digital camera system. In a separate experiment, in order to validate that parasitoid maternal fluids are directly responsible for the generation of intracellular ROS, we investigated whether Nacetyl cysteine (NAC) had an effect on the increase production of ROS in activated hemocytes (Cotter 2007; Felton et al. 2009). The control group and the activated hemocytes were subjected to an NAC (5 mM) pre-treatment (Sigma, St. Louis, Mo., USA), which was performed according to the method suggested by Cotter (2007), prior to parasitization. ROS in hemocytes was measured after NAC treatment following the same procedures described earlier. The effect of NAC was assessed by the rate of conversion of 5-carboxy-2',7'-dichorodihydrofluorescein diacetate (carboxy- $\mathrm{H}_{2}$ DCFDA) to its reduced fluorescent configuration.

\section{Melanin detection}

\section{Periodic acid-silver methenamine staining procedure}

Melanin, a sulfur-rich protein is ultrastructurally demonstrated by using the periodic acid-silver methenamine (PASM) staining procedure (Moellmann et al. 1988). In addition, in order to validate the presence of melanin, a destaining of thin sections for $5 \mathrm{~min}$ in 3\% hydrogen peroxide was performed (Pearse 1972; Knight and Lewis 1980; Moellmann et al. 1988; Korytowsky and Sarna 1990). Hydrogen peroxide specifically removed melanin, decolorizing the area occupied by the protein.

\section{Acid phosphatase localization}

Ultrastructural localization of acid phosphatase (AcPase; an enzyme present in elevated concentration in melanosomes during the melanization phase) was performed on samples fixed for $1 \mathrm{~h}$, at $4{ }^{\circ} \mathrm{C}$, in $1.5 \%$ sodium-cacodylate-buffered glutaraldehyde. Hemocytes, washed in $50 \mathrm{mM}$ sodium cacodylate buffer, were incubated in a medium according to Barka and Anderson (1977) for $2 \mathrm{~h}$ at $37^{\circ} \mathrm{C}$. The cells were then post-fixed in $1 \% \mathrm{OsO}_{4}$ in sodium cacodylate buffer, dehydrated, and embedded as previously described. A negative control for enzyme activity was carried out by omitting the substrate. 
Immunocytochemistry

\section{ACTH, $\alpha-M S H, N E P$, and interleukin 18 localization}

The presence of ACTH and its cleavage product (because of NEP activity) $\alpha$-MSH (responsible for the stimulation, production, and release of melanin) and of the pro-inflammatory interleukin 18 (IL-18) were assessed by using the following primary antibodies: anti-human ACTH polyclonal antibody (1:50 dilution, Sigma); anti-human $\alpha$-MSH polyclonal antibody (1:50 dilution, Sera-lab, Crawley Down, UK); antihuman IL-18 polyclonal antibody (1:50 dilution, Santa Cruz Biotechnology, Santa Cruz, Calif., USA); anti-human CD10/ CALLA (NEP) monoclonal antibody (clone 56C6, diluted 1:50, Thermo Scientific, Freemont, Calif., USA).

Incubations with suitable secondary antibodies conjugated with tetramethylrhodamine (TRITC; 1:200 dilution, Jackson, Immuno Research Laboratories, West Grove, Pa., USA) were performed for $1 \mathrm{~h}$ in a dark humid chamber. Nuclei were stained with 4',6-diamidino-2-phenylindole (DAPI, Sigma, Italy). The PBS buffer used for washing steps and antibody dilutions contained $2 \%$ bovine serum albumin (BSA). In control samples, primary antibodies were omitted, and samples were treated with BSA-containing PBS. Coverslips were mounted in Vectashield mounting medium for fluorescence (Vector Laboratories, Burlingame, Calif., USA). Slides were observed either under a confocal laser microscope (laser set at $568 \mathrm{~nm}$ for rhodamine; MRC 1024, Bio-Rad Laboratories, Hemel Hempstead, UK) with $\times 40$ and $\times 63$ objectives (NA $1.30,1.25$ ) or under an Olympus BH2 microscope (Olympus, Tokyo, Japan).

\section{Amyloid fibrils-NEP axis}

NEP is an important amyloid-degrading enzyme (Iwata et al. 2004; Wang et al. 2006; El-Amouri et al. 2008; Hafez et al. 2011). This endopeptidase is highly sensitive to potent inhibition by phosphoramidon (PhO), which induces substantial fibril accumulation (Hafez et al. 2011). According to the Hafez method (Hafez et al. 2011), H. virescens hemolymph was pretreated, before parasitization, with $\mathrm{PhO}$ $(10 \mu \mathrm{M})$ in order to investigate the in vivo role of NEP in amyloid fibril degradation. The expected accumulation of fibrils, as evidenced by staining with thioflavine $T$, was used to validate the blockage of enzymatic activity.

\section{Biochemical procedures}

Whole homogenized hemolymph was suspended in extraction buffer $(0.4 \mathrm{M} \mathrm{NaCl}, 5 \mathrm{mM} \mathrm{MgCl}, 1 \mathrm{mM}$ EDTA, $50 \mathrm{mM}$ TRIS HCl, pH 7.2, with freshly added $1 \mathrm{mM}$ phenylmethylsulfonyl fluoride and $0.2 \mathrm{mM} \mathrm{ATP}$ ), and particulate material was removed by centrifugation at $13,000 \mathrm{rpm}$ for $10 \mathrm{~min}$ at $4^{\circ} \mathrm{C}$ in a refrigerated Sorvall RCM14 microcentrifuge. Supernatants were denatured in sample buffer 2 ( $2 \%$ SDS, $10 \%$ mercaptoethanol, $0.002 \%$ bromophenol blue, $20 \%$ glycerol, $0.02 \mathrm{M}$ TRIS $\mathrm{HCl}, \mathrm{pH} 6.8$ ) at $100^{\circ} \mathrm{C}$ for $5 \mathrm{~min}$. Protein quantitation was performed according to Bradford (1976) with the spectrophotometer "Helios" (Spectronic Unicam, Cambridge, UK). BSA was utilized as a standard. After protein quantitation, SDSpolyacrylamide gel electrophoresis (SDS-PAGE) was carried out: samples were added to a PAGE buffer $(12.5 \%$ $0.5 \mathrm{M}$ TRIS- $\mathrm{HCl} \mathrm{pH} 6.8,10 \%$ glycerol, $2 \%$ SDS, $0.5 \%$ 2mercaptoethanol, $0.025 \%$ bromophenol blue) to give a final protein dilution of approximately $5 \mu \mathrm{g} / \mu \mathrm{l}$ for each sample, and, after a boiling step (4 min), $20 \mathrm{mg}$ protein was loaded into each lane, separated by SDS-PAGE (15\% separating gel, 4\% stacking gel; Laemmli 1970), and blotted onto polyvinylidene difluoride membranes $(0.2-\mathrm{mm}$ pore size) An anti-human ACTH polyclonal antibody (1:1000 dilution, Sigma), an anti-MSH polyclonal antibody $(1: 1000$; Seralab), and anti-human CD10/CALLA monoclonal antibody (diluted 1:500, Thermo Scientific) were used as primary antibodies. Immunoreactive bands were visualized after incubation with a alkaline-phosphatase-conjugated secondary antibody (Vector Laboratories) by using an nitroblue tetrazolium (NBT)/5-bromo-4-chloro-3-indolyl-phosphate (BCIP) detection system.

\section{Results}

In order to study the morpho-functional modifications that occur in hemocytes after parasitization, we have examined circulating hemocytes from unparasitized and parasitized $H$. virescens at $2 \mathrm{~h}$ after oviposition according to Ferrarese and coworkers (2005). This represents the shortest time in which to acheive the maximum effect linked to parasitization and also to be able to observe, "from the top", any induced phenotype.

\section{Unparasitized $H$. virescens}

\section{Morphology and behavior of hemocytes}

Plasmatocytes and granulocytes (Fig. 1a) are defined as the main larval cell types involved in all defense processes (Beaulaton and Monpeyssin 1977; Brehélin and Zachary 1983; Gupta 1985; Hillyer and Christensen; 2002; Giulianini et al. 2003; Hillyer et al. 2003; Ferrarese et al. 2005; Castillo et al. 2006; Ribeiro and Brehelin 2006). Plasmatocytes are ovoid cells, generally variable in size and showing, by SEM, a few small thin irregular processes at the tapering ends (Fig. 1b). Granulocytes are the most frequently observed larval cell type and are spherical cells, generically identified by small membrane-enwrapped 


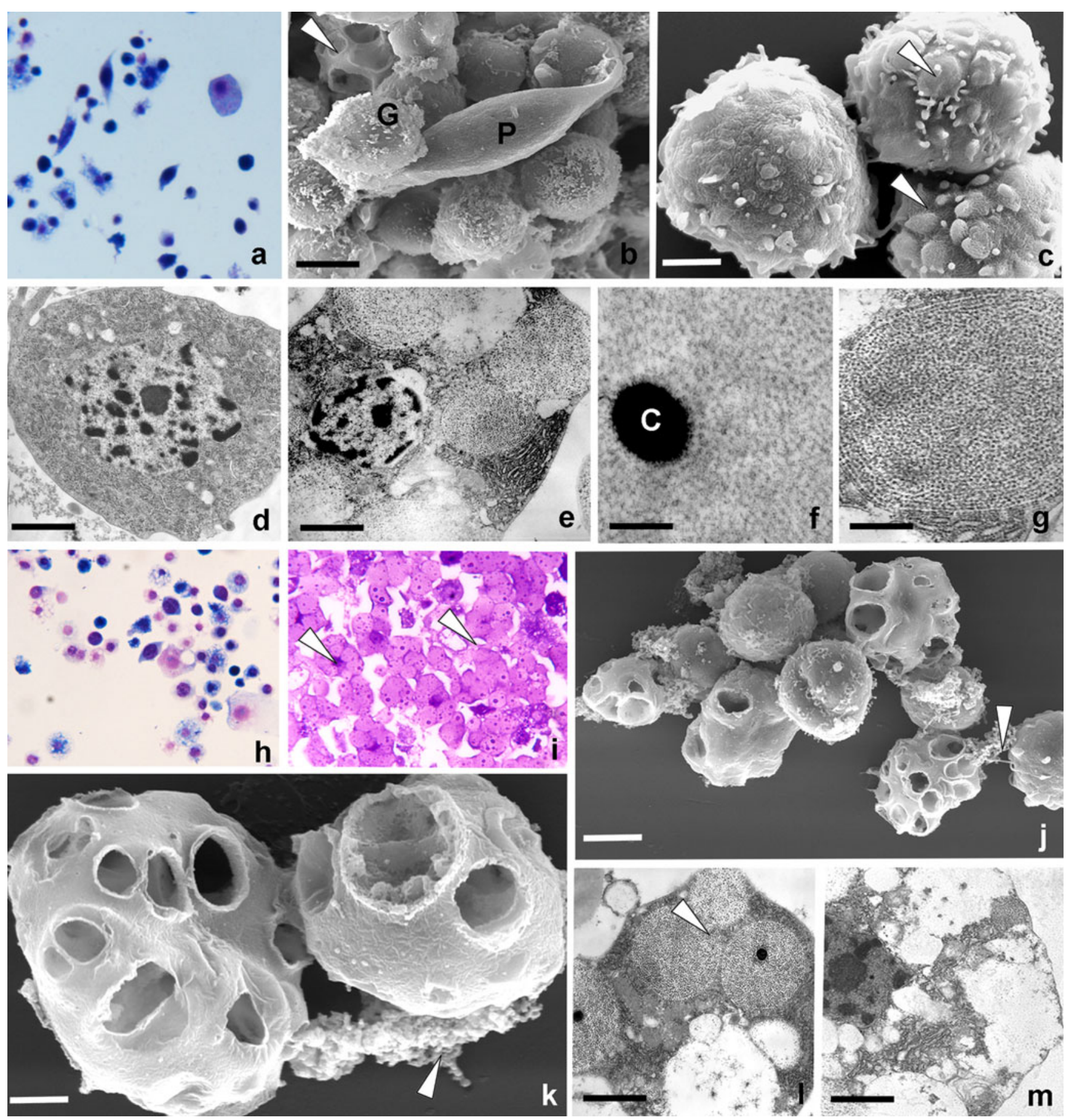

Fig. 1 Circulating hemocytes from unparasitized and parasitized $H$. virescens larvae. a-g Optical and ultrastructural images of control (unparasitized) circulating insect cells. a Light microscopy of hemocytes stained by the May-Grünwald Giemsa technique. b, c Scanning electron microscopy (SEM) of various identifiable types of cell: oval plasmatocytes $(P)$ and roundish granulocytes $(G)$. Most of the granulocytes are characterized by a few short microvilli on the plasma membrane. Some of them show globoid protuberances (upper arrowhead) and occasionally large craters (lower arrowhead). $\mathbf{d}-\mathbf{g}$ Transmission electron microscopy (TEM) of unactivated granulocytes (d) and activated granulocytes ready to exocytose (e). The activated cell shows significant morphological changes at the cytoplasmic level (e-g) by displaying large dilated reticulum cisternae (e) filled with spatially organized fibrillar material $(\mathbf{e}-\mathbf{g})$. The fibrillar material forms a lattice around an electron-dense core $(C$ in f). $\mathbf{h}-\mathbf{m}$ Optical and ultrastructural images of insect parasitized/activated circulating cells. h, i Light microscopy of hemocytes. h Hemocytes stained by the May-Grünwald Giemsa technique. Note the differential staining of granulocytes depending on cytoplasmic $\mathrm{pH}$. i Semithin section of hemocytes in which most of the granulocytes show morphological modification attributable to the presence of large filled cisternae (arrowheads) surrounding the nuclei. $\mathbf{j}-\mathbf{m}$ SEM and TEM of the various phenotypes of granulocytes from parasitized $H$. virescens. A few granulocytes are ready to undergo exocytosis $(\mathbf{j}, \mathbf{l})$ showing large amounts of synthesized material within cisternae (I), whereas most of the cells have undergone exocytosis. The "containers" of fibrillar material are empty $(\mathbf{j}, \mathbf{l}, \mathbf{m})$, and their product is visible between the cells (arrowheads in j, k). Bars $3 \mu \mathrm{m}(\mathbf{b}), 2.3 \mu \mathrm{m}(\mathbf{c}), 2 \mu \mathrm{m}(\mathbf{d}$, e), $200 \mathrm{~nm}(\mathbf{f}), 300 \mathrm{~nm}(\mathbf{g}), 4 \mu \mathrm{m}(\mathbf{j}, \mathbf{k}), 1 \mu \mathrm{m}(\mathbf{l}, \mathbf{m})$ 
granules within the cytoplasm. The plasma membrane of most of the granulocytes is smooth or possesses short microvilli (Fig. 1b) or sometimes exhibits roundish protrusions corresponding to a large amount of material pushing out the plasma membrane (Fig. 1c) and only occasionally extremely large bowl-shaped depressions in the surface attributable to massive exocytosis (Fig. 1b).

TEM analysis showed that the majority of granulocytes $(80 \%)$ had a disk shape in which the nucleus occupied the center of the cell. The cytoplasm was occupied by rough endoplasmic reticulum, Golgi apparatus, mitochondria, glycogen, vacuoles, and a few small homogenous granules (Fig. 1d). Occasionally, a few granulocytes revealed that their cytoplasm was particularly occupied by fibrillar material spatially organized with respect to an electron-dense body (Fig. 1e-g) and compartmentalized by membranes of rough reticulum (Fig. 1g). Each fibril appeared with a cylindrical cross-sectioned diameter of about $100 \AA$ (Fig. 1f, g). The filled dilated reticulum cisternae were located around the nucleus and concealed the cytoplasmic organules (Fig. 1e).

\section{Parasitized $H$. virescens}

Three aspects were considered:

(1) Morphology and behavior of hemocytes and of amyloid fibril formation

(2) Melanogenesis, melanin-amyloid system, and the ACTH activation system

(3) Clearance activity in the hemocel

\section{Morphology and behavior of hemocytes and of amyloid fibril formation}

Optical, SEM, and TEM analyses (Fig. 1h-m) showed that, whereas plasmatocytes maintained the morphological characteristics previously described for unparasitized animals, parasitization involved mainly granulocytes. Indeed, approximately $80 \%$ of the cells, even though they maintained a round shape with a centrally located nucleus, presented large structured material filling the reticulum cisternae, similar to that rarely observed in unparasitized insects; the structured material took up almost all of the cytoplasm prior to exocytosis (Fig. 1h-m). This prevalent granulocyte phenotype seemed to be characterized by swollen superficial areas (Fig. 1j), corresponding to those cisternae containing massive quantities of a spatially well organized fibrillar material (Fig. 1i, 1) forming a lattice of parallel elements positioned around an electron-dense core (Fig. 11). Some cells had large empty craters, due to exocytosis (Fig. 1j, k). The discharged fibrillar material was visible close to those cells showing surface features of exocytosis (Fig. 1j, k).
Organelles within the cytoplasm became identifiable, especially in concomitance with the exocytosis of the large amount of fibrillar compartmentalized material (Fig. 11, $\mathrm{m})$. The granulocyte cytoplasm was filled with a massive amount of fibrillar material (Fig. 2a-d) forming compact spheres readily identifiable once the cell membrane had been removed (Fig. 2b, d). In cells in which the membrane had been removed, this material showed a clear fibrillar structure that was apparent after exocytosis (Fig. 2c, d) in comparison with the usually limited amount observable in the unparasitized $H$. virescens.

\section{Melanogenesis, melanin-amyloid system, and ACTH activation system}

We used PASM, a selective stain, in order to localize sulfurrich proteins, such as melanin, in the electron microscope. In thin sections of hemocytes, the electron-opaque deposits of silver were loosely distributed and scattered in association with the filamentous material within the expanded dilated rough reticulum cisternae occupying the cytoplasm of granulocytes (Fig. 2e, f). The presence of melanin was also identified by destaining thin sections with hydrogen peroxide (Pearse 1972; Knight and Lewis 1980; Moellmann et al. 1988); this method specifically removed melanin, thereby decolorizing the area occupied by the protein that was localized interspersed in the fibrillar material but especially in the electron-dense central "cores" that were generally found at the center of each dilated cisternae of the activated granulocytes (Fig. 2g). Cytochemical ultrastructural studies were also conducted to identify the possible site of melanin deposition and inherent AcPase production (the enzyme was generally present in elevated concentration in melanosomes during the melanization phase; Barka and Anderson 1977; Nakagawa et al. 1984; Diment et al. 1995). AcPase activity was detected inside and outside the granulocyte cells (Fig. $2 \mathrm{~h}-\mathrm{j}$ ). The enzyme was identified by the finely particulate and extremely dense products of the cytochemical reaction. Extremely small amounts of AcPase precipitates were seen rather sparsely in the dilated cisternae (Fig. 2h), whereas the most concentrated precipitates were seen associated with extracellular fibrils (Fig. 2i). In controls (incubated without substrate), these precipitates were absent from the fibrillar material (Fig. 2j).

Glycosaminoglycans, a constant component that generally accompanies amyloid fibril formation, were revealed in hemocytes (Fig. $2 \mathrm{k}, \mathrm{m}$ ) that were stained with safranin and Alcian Blue. In the middle of areas occupied by fibrils, the round core was positive for safranin (Fig. 21) and Alcian Blue (Fig. 2m).

Unlike unparasitized $H$. virescens, the parasitized larvae showed mostly pink granulocytes (Fig. 1a, h) after MayGrünwald Giemsa differential staining, thus indicating a 


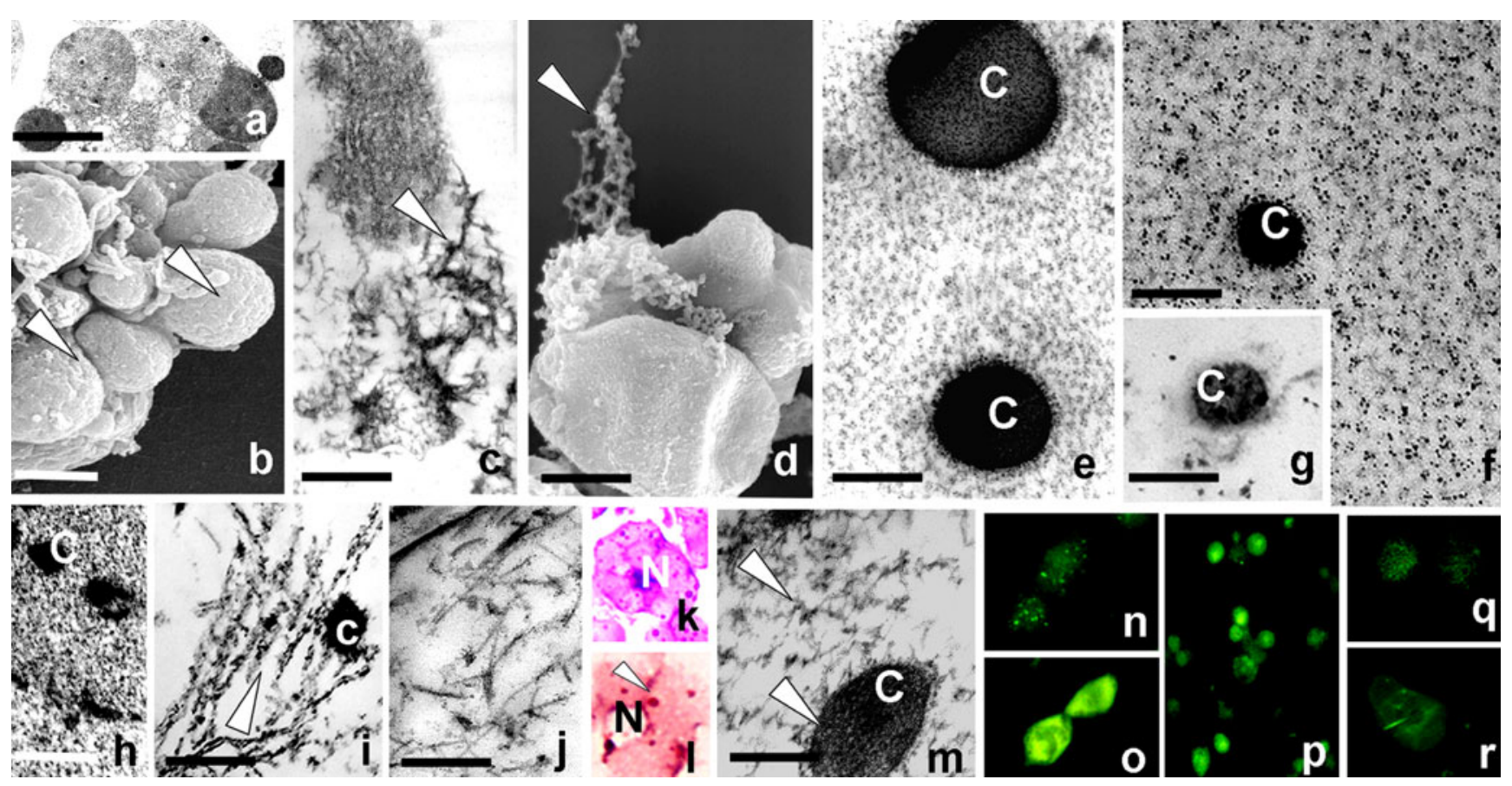

Fig. 2 Characterization of granulocytes from parasitized $H$. virescens larvae. a-e SEM and TEM of granulocyte cytoplasm from parasitized $H$. virescens. The cytoplasm is characterized by rough endoplasmic reticulum arranged in layers and showing, in relation to exocytosis activity, several enlarged cisternae that are either filled with amyloid fibrils (a) spatially organized around an electron-dense core ( $C$ in e) or practically empty. The amyloid material forms large compact structures easily visible in the three-dimensional view of the "skinned" cell (b, arrowheads) or it shows a fibrillar shape after exocytosis (c, d, arrowheads). $\mathbf{f}-\mathbf{j}$ TEM showing the localization of melanin. The pigment is revealed by periodic acid-silver methenamine staining (f). Electrondense reaction products are scarce and interspersed among amyloid fibrils (f), which are especially associated with the roundish central electron-dense core $(C)$. Melanin presence is also validated by destaining thin sections (g) with hydrogen peroxide. The decolorized area attributable to the removed melanin is localized among the fibrillar material and especially in the electron-dense core $(C)$. $\mathbf{h}-\mathbf{j}$ The possible sites of melanin deposition are identified by the localization of inherent acid phosphatase (AcPase) reaction products that are distributed in the dilated cisternae and mixed with fibrillar components (h) or are

change in the cytoplasmic $\mathrm{pH}$. The formation of intracellular ROS was monitored by preloading the cells with $\mathrm{H}_{2}$ DCFDA, which fluoresces on exposure to any oxidant. ROS production in the hemocytes was detected by the increasing cytoplasmic fluorescence of DCF after contact with maternal fluid. The fluorescence, which was weak and spotted in a few control hemocytes (Fig. 2n), peaked in parasitized $H$. virescens hemocytes (Fig. 2o, p). NAC significantly buffered and/or neutralized ROS levels induced by the activation of hemocytes (Fig. 2q). Hemocytes treated with NAC alone showed no effects in terms of ROS production (Fig. 2r).

In parasitized/activated hemocytes characterized by an overproduction of ROS, an apparent activation of stress circuits occurred that resulted (with respect to unparasitized "glued" to the exocytosed amyloid fibrils (i, arrowhead). j Control (j). k-m Optical microscopy and TEM showing the cytochemical localization of glycosaminoglycans in activated granulocytes. Amyloid fibrils, filling the endoplasmic cisternae surrounding the nucleus $(N)$ are stained (k) with conventional or (i) with safranin selective methods. The weak positivity (reddish tinge) is localized within the space occupied by amyloid material, and the signal is strong at core level (arrowheads). Glycosaminoglycans, stained by the Alcian Blue technique, are ultrastructurally visualized in the reticulum cisternae, being especially localized in the central core ( $C$, arrowheads in m). Bar $300 \mathrm{~nm}(\mathbf{m})$. n-r Reactive oxygen species (ROS) generation was detected by monitoring the increase in fluorescence (green) of the oxidized dye $\mathrm{H}_{2}$ DCFDA. The escalation in ROS level is evident by comparing control granulocytes (n) with those from parasitized $H$. virescens larvae $(\mathbf{o}, \mathbf{p})$. N-acetylcysteine (NAC) prevents ROS formation. The granulocytes treated pre-parasitization with NAC (q) and those treated with NAC alone (r) appeared similar to those of control cells (n), which showed a weak spotted fluorescent signal. Bars $1.7 \mu \mathrm{m}$ (a), $2 \mu \mathrm{m}(\mathbf{b}, \mathbf{d}), 400 \mathrm{~nm}(\mathbf{c}, \mathbf{j}), 300 \mathrm{~nm}(\mathbf{e}, \mathbf{g}), 200 \mathrm{~nm}(\mathbf{f}), 1 \mu \mathrm{m}(\mathbf{h})$, $600 \mathrm{~nm}(\mathbf{i})$

larvae; Fig. 3a, d) in a massive presence of ACTH and $\alpha$ MSH (Fig. 3b, e) as demonstrated by immunohistochemical staining. Almost all hemocytes were ACTH- and $\alpha$-MSHpositive (Fig. 3b, e). The NEP enzyme (Fig. 3g-i), responsible for the conversion of ACTH into $\alpha$-MSH (DuvauxMiret et al. 1992; Ottaviani et al. 1997; Caselgrandi et al. 2000; Slominski et al. 2005), was detected in activated hemocytes within the hemocel (Fig. 3h-i). On the contrary, in unparasitized (i.e., unactivated/unstressed) hemocytes, NEP immunoreactivity was scarce (Fig. 3g). The specificity of antibodies directed against these peptides was confirmed in Western blotting experiments. The anti-ACTH labeled a band of about $5.0 \mathrm{kDa}$, the anti- $\alpha$-MSH detected a band at about $2 \mathrm{kDa}$, while the anti-NEP showed a band of about 80 $\mathrm{kDa}$ (Fig. 3q). 

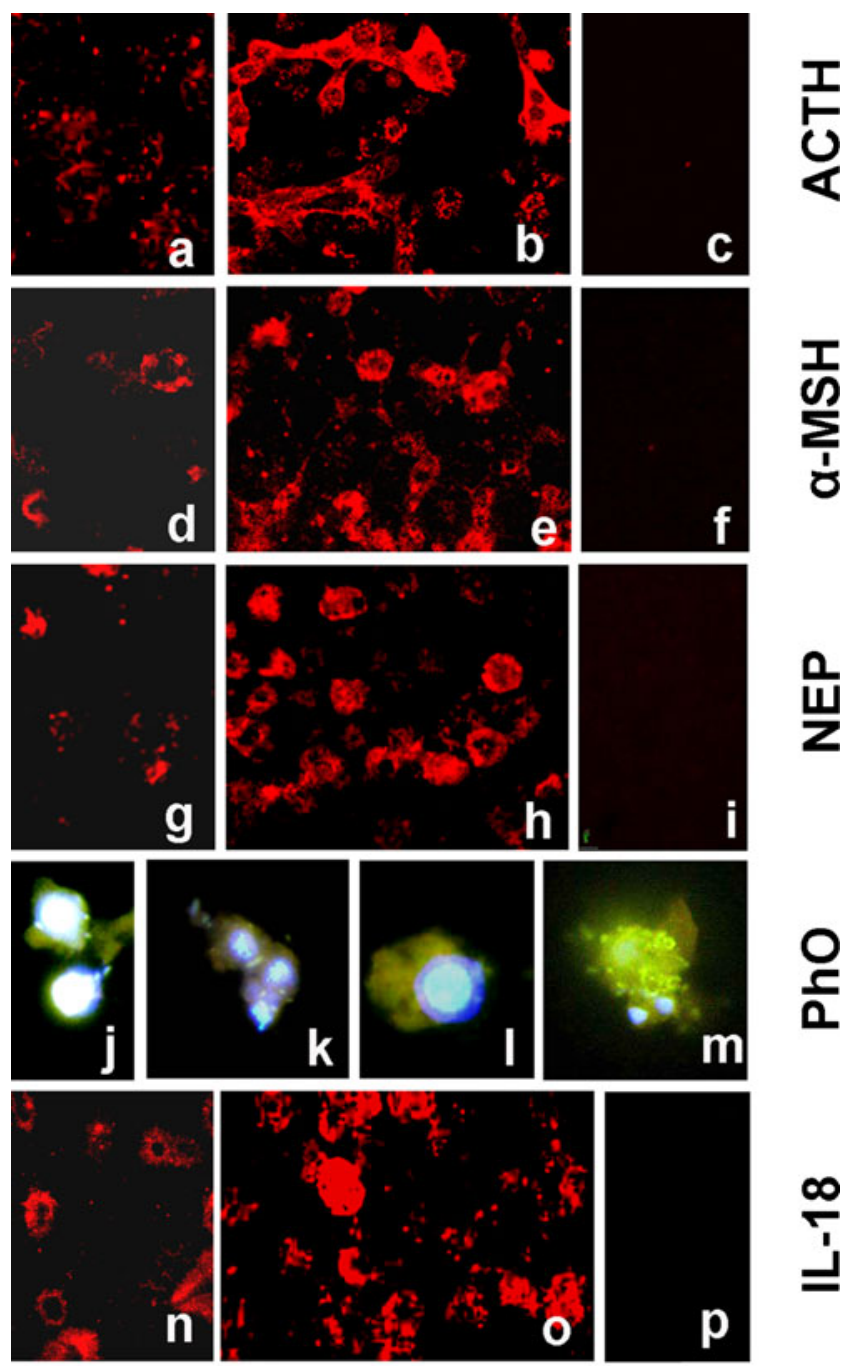

$\stackrel{\infty}{=}$

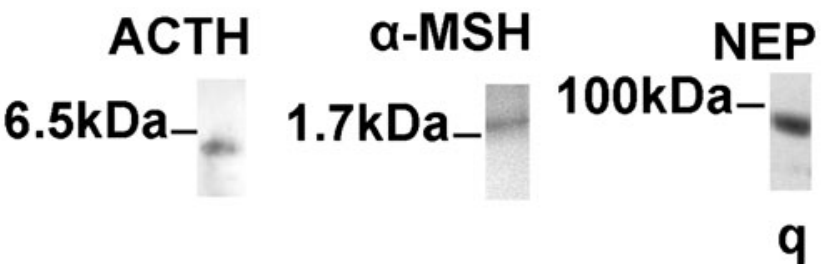

Fig. 3 Characterization of granulocytes from $H$. virescens larvae. $\mathbf{a}-\mathbf{p}$ Immunocytochemical characterization of adrenocorticotropin hormone $(A C T H ; \mathbf{a}-\mathbf{c})$, alpha melanocyte-stimulating hormone $(\alpha-$ $M S H ; \mathbf{d}-\mathbf{f})$, neutral endopeptidase (NEP; $\mathbf{g}-\mathbf{i})$, and interleukin 18 (IL-18; n-p) showed high positivity, especially in granulocytes from parasitized $H$. virescens; the expression of ACTH (a), $\alpha$ MSH (d), NEP (g), and IL-18 (n) in hemocytes from unparasitized larvae was lower than ACTH (b), $\alpha$-MSH (e), NEP (h), IL18 (o) in stimulated cells. $\mathbf{j}-\mathbf{m}$ Immunocytochemical evidence of amyloid fibrils detected with thioflavin $\mathrm{T}$ (yellow-green). The endopeptidase NEP responsible for amyloid fibril degradation is inhibited by phosphoramidon $(P h O)$, which induces substantial fibril accumulation within $(\mathbf{k}, \mathbf{l})$ and outside $(\mathbf{m})$ granulocytes. $\mathbf{j}$ Granulocytes from untreated larva. c, f, i, p Control samples: primary antibodies were omitted, and samples were treated with phosphate-buffered saline containing bovine serum albumin. q Western Blot analysis of ACTH, $\alpha-\mathrm{MSH}$, and NEP immunoreactivity in lepidopteran hemolymph

\section{Clearance activity in hemocel}

In vertebrates, $\mathrm{NEP}$ is involved not only in $\mathrm{ACTH} / \alpha-\mathrm{MSH}$ regulation signaling, but also in the modulation of other active peptides of biological interest in relation to its location: NEP antigen has been detected in fibroblast granules (Johnson et al. 1985; Lorkowski et al. 1987; Cohen et al. 1996; Kubiak-Wlekły and Niemir 2009), in epithelial cells, in kidney, in intestinal microvilli, and in the human brain. In the last-mentioned, NEP is responsible for the degradation of amyloid fibrils maintaining a steady state level of biosynthetic product and preventing their accumulation and deposition into plaques that, in turn, cause pathogenic effects (El-Amouri et al. 2008; Glabe 2000). Keeping in mind that, in our invertebrate model after stimulation and amyloid/melanin production, the hemolymph regains its initial transparent clearness, we investigated the relationship between the presence of NEP and amyloid clearance (Arora et al. 2004; Meilandt et al. 2009; Hafez et al. 2011) by using a specific potent inhibitor of the enzyme, i.e., PhO (Fig. 3j$\mathrm{m})$. Indeed, $\mathrm{PhO}$ provokes, with respect to unstimulated hemocytes (Fig. 3j), an accumulation of amyloid fibrils that are thioflavin-positive inside and outside of the cells (Fig. 3k$\mathrm{m})$. Finally, parasitization increases pro-inflammatory cytokines such as IL-18 levels (Fig. 3n-p). The stimulation and production of this important cytokine is considered an essential step for the activation of an innate defense, since it is involved in chemotaxis, adhesion, and exocytosis (Remick 2005; Baune et al. 2008) and is a predictor-molecule in AD (Alboni et al. 2010; Bossù et al. 2010).

\section{Discussion}

Upon T. nigriceps oviposition, the host larva receive the wasp egg equipped with factors of maternal origin (i.e., a mixture of ovarian proteins, venom, and polydnaviruses) that induce severe impairment of the host immune and neuroendocrine systems (Pennacchio et al. 2001; Ferrarese et al. 2005; Pennacchio and Strand 2006; Falabella et al. 2012).

In the present study, we have observed that morphofunctional alterations of activated host hemocytes are essential to induce a massive production of amyloid fibrils, a phenomenon associated with several crucial events.

During the first $2 \mathrm{~h}$ after parasitization, two important transient events are known to occur: (1) a reduction in the phenoloxidase activity (i.e., an inhibition of the most important melanization event), and (2) an alteration of the number and/or behavioral modification of the circulating hemocytes.

The plasmatocytes together with granulocytes represent the larval circulating immune cells. The first type maintains the morphological characteristics described for unparasitized 
animals, whereas many cells of the second type are characterized by having large vacuoles in their cytoplasm (Ferrarese et al. 2005; Falabella et al. 2012). Here, we focus on the morphological modifications that occur in granulocytes that, as observed by SEM and TEM, show superficial bulges pushing out the plasma membrane; such bulges contain fibrillar material forming a lattice that is compartmentalized by membranes of rough reticulum. Fibrils can be found discharged close to the exhausted granulocytes that then exhibit large craters. Whereas in unparasitized $H$. virescens larvae, only an extremely small percentage of granulocytes shows this phenotype, in the parasitized host, almost all granulocytes share these features. The granulocytes activated by parasitization are the major repository of amyloid fibrils (Falabella et al. 2012). Furthermore, the injection of parasitoid maternal fluids with the eggs acts as a stimulant. Indeed, extracted hemocytes that have come into contact with ovarian proteins at a concentration of 2 female-equivalents/ml and examined after $2 \mathrm{~h}$ of incubation show the same phenotype as "natural" parasitized hemocytes (P. Falabella, unpublished data). The fibrillar material forms a regular periodic configuration surrounding a seeding electron-dense "core" composed of proteoglycans and containing a modest amount of melanin, which is also present in small quantities inside the cell, interspersed among amyloid fibrils, although its massive formation usually occurs in the hemocel.

In addition to the evidence that amyloid fibrils are physiologically involved both in vertebrate and insect melanogenesis (Fowler et al. 2006; Falabella et al. 2012), and taking into account that the cross-beta sheet structure of amyloid is necessary to provide a template for melanin deposition, we have examined in detail the series of events that occur in $H$. virescens compared with those observed in vertebrates. In the latter, the earliest events preceding the formation of amyloid fibrils are the production of ACTH (responsible for the autocrine/paracrine activation of cells) and of $\alpha$-MSH (resulting in the activation of melanin production; Brady et al. 2001) and ROS overproduction inducing proteins to adopt a $\beta$-sheet conformation (Christen 2000; Drake et al. 2003; Slominski et al. 2005; El-Amouri et al. 2008). A controlled ROS level is fundamental for the coordination of many physiological cellular processes. However, its increased production linked in $H$. virescens hemocytes to parasitization [as validated by results from experiments with the antioxidant NAC (Cotter 2007; Felton et al. 2009) and detected by the peaked cytoplasmic fluorescence of DCF] can be interpreted as the key event promoting amyloid fibril formation. In this context, an interrelationship between melanization, AcPase activity engaged in pigment synthesis, and an extremely acidic intramelanosomal pH is required (Nakagawa et al. 1984; Moellmann et al. 1988; Diment et al. 1995). In our model, the granulocytes activated by parasitization produce a large amount of amyloid fibrils to package melanin, and in this process, the main events specifically linked to immune responses (cited above) are involved. Indeed, the production and assemblage of amyloid fibrils in the reticulum cisternae is intimately related to, and controlled by, extrinsic and intrinsic factors. The stimulation in response to parasitic attack involves cross-talk between the immune and neuroendocrine systems mediated by hormones, cytokines, and neuromodulators with the activation of stress-sensoring circuits to produce and release molecules such as ACTH, $\alpha$ $\mathrm{MSH}$, and NEP. Among the intrinsic factors, ACTH
Fig. 4 Representation to explain the possible behavior of host hematocytes after parasitization. T. nigriceps maternal fluids, co-injected with eggs, are responsible of an integrated network of events starting with an increase in ROS levels. Oxidative stress, in turn, leads to ACTH, $\alpha-\mathrm{MSH}$, and NEP augmentation and induces IL-18 production and amyloid fibril formation. NEP might be involved both in the conversion of ACTH into $\alpha$-MSH and in the removal of amyloid fibrils within the host hemocoel. The enzymatic degradation of fibrillar material is a clearance mechanism to ensure a healthy environment for the development of the parasitoid egg

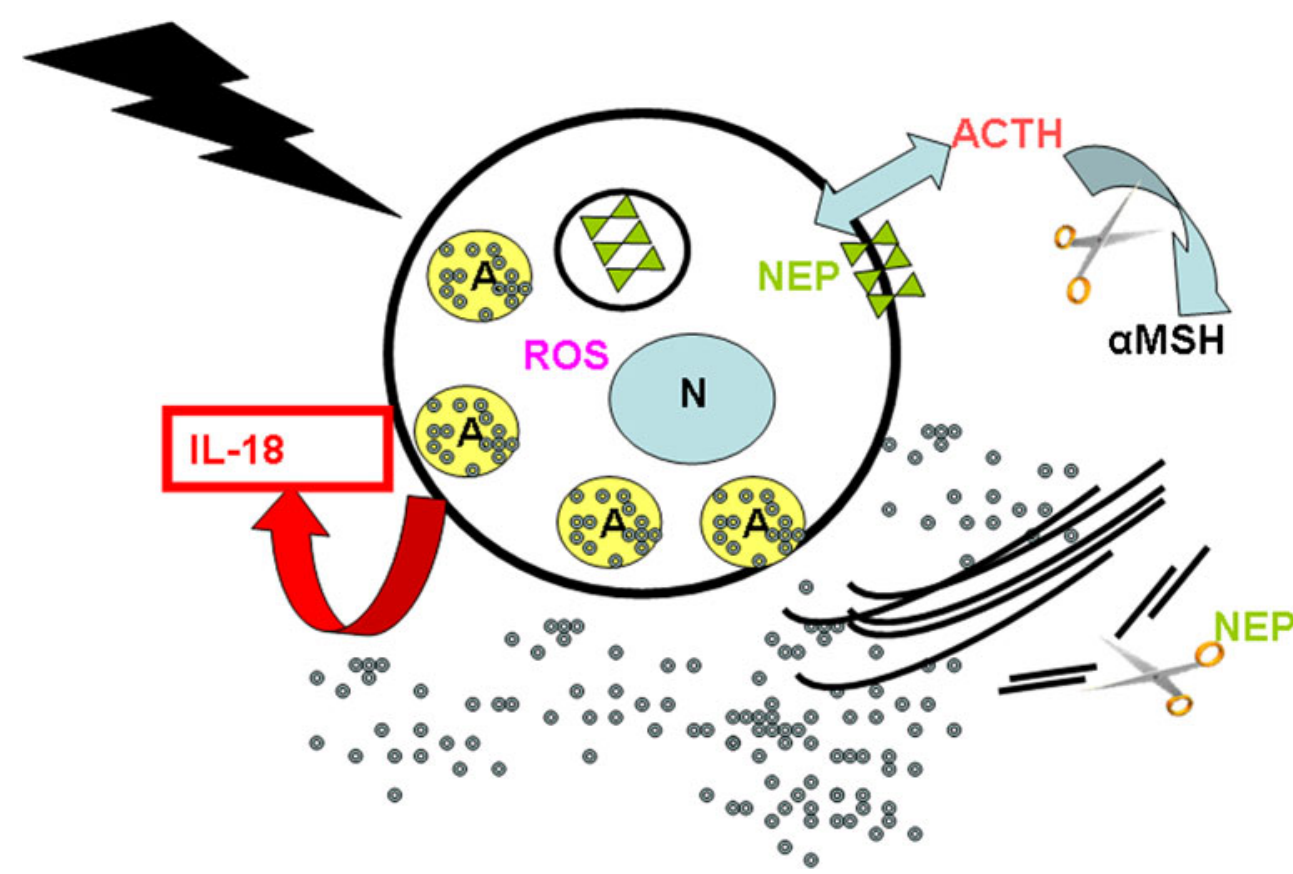


production and the expression of pro-inflammatory cytokines such as IL-18 occur. These selected molecules have been detected by our immunostaining studies, and Western blot analysis of hemolymph total protein extract shows the presence of a protein with similar molecular weights to $\mathrm{ACTH}, \alpha-\mathrm{MSH}$, and NEP as detected in vertebrates. These data are in agreement with those from protostomian studies of several animals belonging to various taxa of invertebrates: flatworms, insects, molluscs, and annelids (Verhaert et al. 1984; Duvaux-Miret et al. 1992; Genedani et al. 1994; Ottaviani et al. 1995; Franchini et al. 1996; Salzet et al. 1997; Salzet 2000; Malagoli et al. 2011).

Among the plethora of interleukins, IL-18 not only is an "ancient" and important molecule responsible for the activation of effective innate defense, but also is involved in vertebrate amyloidogenesis, i.e., in physiopathological processes of the brain, such as $\mathrm{AD}$ (Alboni et al. 2010; Bossù et al. 2010; Alboni et al. 2011). All the steps of the various activations, as previously reported, are sustained by an overproduction of ROS, which is responsible for the variation in pH (Christen 2000; Squier 2001; Zhu et al. 2004; Chen et al. 2005; Du and Yan 2010).

In summary (Fig. 4), we propose that, at the single circulating cell level, multiple activation sequences occur in response to parasitization, which can be considered as a stress condition. The injection of parasitoid eggs with maternal fluid, which is responsible of ROS generation, switches on the ACTH-NEP$\alpha$-MSH axis, which is present in hemocytes (i.e., granulocytes) that are able to regulate the activation of melanin and its correlated amyloid production. ACTH $/ \alpha-\mathrm{MSH}$ loop modulation is finely tuned by the NEP enzyme present on the cell surface. This enzyme is another aspect of the complex interrelationship of the neuroendocrine and immune systems: after the exocytosis of amyloid fibrils (finalized as a template for melanin) and the lysis of the granulocyte, NEP massively hydrolyzes the amyloid fibrils poured into the circulating fluid, and this cleavage (as validated by using a specific inhibitor abolishing the degrading ability of the enzyme; Hafez et al. 2011) prevents an unnecessary accumulation of amyloid resistant material in the hemolymph.

On the whole, these series of events take place in both invertebrates and vertebrates. The key differences in insects with respect to vertebrates is that, in vertebrates, melanin and amyloid fibrils are produced in the same cell (melanocytes; Fowler et al. 2006), whereas in insects, the two processes are disjoined and, even if a modest production of melanin is also visible in the cytoplasm of hemocytes, melanization largely occurs in the hemocel in which the exocytosed amyloid fibrils package the large amount of pigment resulting from humoral pro-phenoloxidase (pro-PO) system reactions (Schmidt et al. 2001; Ferrarese et al. 2005). Phenoloxidase is the enzyme for the massive melanin synthesis that occurs around the non-self invader, which is at least physically isolated within a rigid capsule. The confined pro-PO system action (i.e., melanin synthesis) close to the non-self invader presumably avoids systemic melanization and might be attributable to the large amount of amyloid fibrils discharged from granulocytes. Thus, these fibrils could have a dual function: to enable pigment polymerization and, because of their intrinsic adhesiveness (Mostaert et al. 2006; Mostaert and Jarvis 2007) to "glue" the pigment to the non-self surface.

An expanding body of evidence indicates that parasitic actions are generally aimed at impairing or blocking any kind of immune response, and in agreement with this point of view, the parasitoid $T$. nigriceps switches off the pro-PO cascade, the most important source of host melanin. However, unlike this common behavior, the parasitoid forces the massive exocytosis of amyloid fibrils by the host granulocytes. In the host $H$. virescens, the transient inhibition of the its pro-PO system starts soon after the injection of the parasitoid egg into the $H$. virescens hemocel but the host system slowly regains, after a short time, its normal activity (Ferrarese et al. 2005). We hypothesize that concomintantly (because of maternal fluid action), the parasitoid unloads weapons-granulocytes, stimulating the synchronous overproduction and release of amyloid fibrils when there is no pigment to template. Furthermore, at the end of the transient pro-PO block, the hemocyte number is reduced, and the surviving granulocytes are no longer ready to produce amyloid fibrils fundamental to guaranteeing melanin polymerization. Concurrently, the amyloid fibrils floating in the hemocel are rapidly degraded by NEP that functions as a non-specific enzyme cutting/cleaving the amyloid cargo. Thus, the parasitoid has neutralized two of the most powerful host modes against non-self invasion and guarantees, in a short time, a clean and safe habitat that will be populated with a new cohort of host naive hemocytes ready to recognize the entrance of any type of non-self but unable to recognize the parasitoid that, in the meantime, has strategically concealed and protected itself from them (Grimaldi et al. 2006).

\section{References}

Alboni S, Cervia D, Sugama S, Conti B (2010) Interleukin 18 in the CNS. J Neuroinflammation 7:9

Alboni S, Montanari C, Benatti C, Blom JM, Simone ML, Brunello N, Caggia F, Guidotti G, Marcondes MC, Sanchez-Alvarez M, Conti B, Tascedda F (2011) Constitutive and LPS-regulated expression of interleukin-18 receptor beta variants in the mouse brain. Brain Behav Immun 25:483-493

Arora A, Ha C, Park CB (2004) Inhibition of insulin amyloid formation by small stress molecules. FEBS Lett 564:121-125

Barka T, Anderson PJ (1977) Histochemical methods for acid phosphatase using hexazonium pararosanalin as coupler. J Histochem Cytochem 10:741-753

Baune BT, Ponath G, Golledge J, Varga G, Arolt V, Rothermundt M, Berger K (2008) Association between Il-18 cytokine and 
cognitive performance in an elderly general population-the memo study. Neurobiol Aging 29:937-944

Beaulaton J, Monpeyssin M (1977) Ultrastruscture et cytochimie des hémocytes d'Antheraea pernyi (Guér) (Lepidoptera, Attacidae) au cours du cinquième âge larvaire. J Ultrastruct Res 55:143-156

Bidla G, Lindgren M, Theopold U, Dushay MS (2005) Hemolymph coagulation and phenoloxidase in Drosophila larvae. Dev Comp Immunol 29:669-679

Bossù P, Ciaramella A, Salani F, Vanni D, Palladino I, Caltagirone C, Scapigliati G (2010) Interleukin-18, from neuroinflammation to Alzheimer's disease. Curr Pharm Des 16:4213-4224

Bradford MM (1976) A rapid and sensitive method of the quantitation of microgram quantities of protein utilizing the principle of protein-dye binding. Anal Biochem 72:248-254

Brady BM, Bemis L, Gibbs P, Robinson WA (2001) Alpha-MSH inhibits human melanoma cell migration. Thirty-Seventh Annual Meeting of American Society of Clinical Oncology, May 12-15, 2001, San Francisco, abstract 1434

Brehélin M, Zachary D (1983) About insect plasmatocytes and granular cells. Dev Comp Immunol 7:683-686

Camplejohn KL, Allard S (1988) Limitations of safranin "O" staining in proteoglycan-depleted cartilage demonstrated with monoclonal antibodies. Histochemistry 89:185-188

Caselgrandi E, Kletsas D, Ottaviani E (2000) Neutral endopeptidase24.11 (NEP) deactivates PDGF- and TGF- $\beta$-induced cell shape changes in invertebrate immunocytes. Cell Biol Int 24:85-90

Castillo JC, Robertson AE, Strand MR (2006) Characterization of hemocytes from the mosquitoes Anopheles gambiae and Aedes aegypti. Insect Biochem Mol Biol 36:891-903

Chen Q, Ding Q, Keller JN (2005) The stationary phase model of aging in yeast for the study of oxidative stress and age-related neurodegeneration. Biogerontology 6:1-13

Christen Y (2000) Oxidative stress and Alzheimer disease. Am J Clin Nutr 71:621-629

Cohen AJ, Bunn PA, Franklin W, Magill-Solc C, Hartmann C, Helfrich B, Gilman L, Folkvord J, Helm K, Miller YE (1996) Neutral endopeptidase: variable expression in human lung, inactivation in lung cancer, and modulation of peptide-induced calcium flux. Cancer Res 56:831-839

Cotter MA (2007) N-acetylcysteine protects melanocytes against oxidative stress/damage and delays onset of UV-induced melanoma in mice. Clin Cancer Res 13:5952-5958

Diment S, Eidelman M, Rodriguez M, Orlow SJ (1995) Lysosomal hydrolases are present in melanosomes and are elevated in melanizing cells. J Biol Chem 270:4213-4215

Drake J, Link CD, Butterfield DA (2003) Oxidative stress precedes fibrillar deposition of Alzheimer's disease amyloid $\beta$-peptide $(1-42)$ in a transgenic Caenorhabditis elegans model. Neurobiol Aging 24:415-420

Du H, Yan SS (2010) Mitochondrial permeability transition pore in Alzheimer's disease: cyclophilin D and amyloid beta. Biochim Biophys Acta 1802:198-204

Duvaux-Miret O, Stefano GB, Smith EM, Dissous C, Capron A (1992) Immunosuppression in the definitive and intermediate hosts of the human parasite Schistosoma mansoni by release of immunoactive neuropeptides. Proc Natl Acad Sci USA 89:778-781

El-Amouri S, Zhu H, Yu J, Marr R, Verma IM, Kindy MS (2008) Neprilysin: an enzyme candidate to slow the progression of Alzheimer's disease. Am J Pathol 172:1342-1354

Falabella P, Riviello L, Pascale M, Di Lelio I, Tettamanti G, Grimaldi A, Iannone C, Monti M, Pucci P, Tamburro A, Eguileor M de, Gigliotti S, Pennacchio F (2012) Functional amyloids in insect immune response. Insect Biochem Mol Biol 42:203-211

Falleiros AMF, Bombonato MTS, Gregorio EA (2003) Ultrastructural and quantitative studies of hemocytes in the sugarcane borer, Diatraea saccharalis (Lepidoptera: Pyralidae). Braz Arch Biol Technol 46:287-294
Felton VM, Borok Z, Willis BC (2009) N-acetylcysteine inhibits alveolar epithelial-mesenchymal transition. Am J Physiol Lung Cell Mol Physiol 297:805-819

Ferrarese R, Brivio M, Congiu T, Grimaldi A, Mastore M, Perletti G, Pennacchio F, Sciacca L, Tettamanti G, Valvassori R, Eguileor M de (2005) Several events during parasitization of Toxoneuron nigriceps vs Heliothis virescens transiently disable host immune defences. Inv Surv J 2:60-68

Fowler DM, Koulov AV, Alory-Jost C, Marks M, Balch WE, Kelly JW (2006) Functional amyloid formation within mammalian tissue. PLoS Biol 4:6-26

Franchini A, Miyan JA, Ottaviani E (1996) Induction of ACTH- and TNF- $\alpha$-like molecules in the hemocytes of Calliphora vomitoria (Insecta, Diptera). Tissue Cell 28:587-592

Genedani S, Bernardi M, Ottaviani E, Franceschi C, Leung MK, Stefano GB (1994) Differential modulation of invertebrate immunocyte motility by CRF, ACTH and its fragments. Peptides 15:203-206

Giulianini PG, Bertolo F, Battistella S, Amirante AG (2003) Ultrastructure of the hemocytes of Chetonischema aeruginosa larvae (Coleoptera, Scarabaeidae): involvement of both granulocytes and oenocytoids in vivo phagocytosis. Tissue Cell 35:243-251

Glabe C (2000) Does Alzheimer disease tilt the scales of amyloid degradation versus accumulation? Nat Med 6:133-134

Greenwald J, Riek R (2010) Biology of amyloid: structure, function and regulation. Structure 18:1244-1260

Grimaldi A, Caccia S, Congiu T, Ferrarese R, Tettamanti G, RivasPena M, Perletti G, Valvassori R, Giordana B, Falabella P, Pennacchio F, de Eguileor M (2006) Structure and function of the extraembryonic membrane persisting around the larvae of the parasitoid Toxoneuron nigriceps. J Insect Physiol 52:870-880

Gupta AP (1985) Cellular elements in the hemolymph. In: Kerkut GA, Gilbert LI (eds) Comprehensive insect physiology biochemistry and pharmacology. Pergamon, Oxford, pp 401-451

Hafez D, Huang JY, Huynh AM, Valtierra S, Rockenstein E, Bruno AM, Lu B, Des Groseillers L, Masliah E, Marr RA (2011) Neprilysin- 2 is an important $\beta$-amyloid degrading enzyme. Am J Pathol 178:306-312

Hillyer JF, Christensen BM (2002) Characterization of hemocytes from the yellow fever mosquito, Aedes aegypti. Histochem Cell Biol 117:431-440

Hillyer JF, Schmidt SL, Christensen BM (2003) Hemocyte-mediated phagocytosis and melanization in the mosquito Armigeres subalbatus following immune challenge by bacteria. Cell Tissue Res 313:117-127

Iwata N, Mizukami H, Shirotani K, Takaki Y, Maramatsu S, Lu B, Gerard NP, Gerard C, Ozawa K, Saido TC (2004) Presynaptic localization of neprilysin contributes to efficient clearance of amyloid-beta peptide in mouse brain. J Neurosci 24:991-998

Johnson AR, Ashton J, Schulz WW, Erdös EG (1985) Neutral metalloendopeptidase in human lung tissue and cultured cells. Am Rev Respir Dis 132:564-568

Knight DP, Lewis PR (1980) General cytochemical methods. In: Glauert AM (ed) Staining methods for sectioned material - practical methods in electon microscopy. North-Holland, Amsterdam New York Oxford, pp 77-135

Korytowsky W, Sarna T (1990) Bleaching of melanin pigments. J Biol Chem 265:12410-12416

Kubiak-Wlekły A, Niemir ZI (2009) The relevance of neprilysin for systemic homeostasis and its involvement in the pathological processes. Pol Merkur Lekarski 27:51-54

Laemmli UK (1970) Cleavage of structural proteins during the assembly of the head of bacteriophage T4. Nature 227:680-685

Lavine MD, Strand MR (2002) Insect hemocytes and their role in immunity. Insect Biochem Mol Biol 32:1295-1309

Lawrence PO, Lanzrein B (1993) Hormonal interactions between insect endoparasites and their host insects. In: Beckage NE, 
Thompson SN, Federici BA (eds) Parasites and pathogens of insects, vol 1. Academic Press, San Diego, pp 59-86

Le Vine H III (1999) Quantification of $\beta$-sheet amyloid fibril structures with thioflavin T. Methods Enzymol 309:274-284

Loof T, Morgelin M, Johanson L, Olin AI, Dickneite G, NorrbyTeglund A, Theopold U, Herwald H (2011) Coagulation, an ancestral serine protease cascade, exerts a novel function in early immune defense. Blood 118:2589-2598

Lorkowski G, Zijderhand-Bleekemolen JE, Erdös EG, Figura K von, Hasilik A (1987) Neutral endopeptidase-24.11 (enkephalinase). Biosynthesis and localization in human fibroblasts. Biochem J 248:345-350

Malagoli D, Accorsi A, Ottaviani E (2011) The evolution of proopiomelanocortin: looking for the invertebrate fingerprints. Peptides 32:2137-2140

Meilandt WJ, Cisse M, Ho K, Wu T, Esposito LA, Scearce-Levie K, Cheng IH, Yu GQ, Mucke L (2009) Neprilysin overexpression inhibits plaque formation but fails to reduce pathogenic Abeta oligomers and associated cognitive deficits in human amyloid precursor protein transgenic mice. J Neurosci 29:1977-1986

Moellmann G, Slominski A, Kuklinska E, Lerner AB (1988) Regulation of melanogenesis in melanocytes. Pigment Cell Res 1:79-87

Mostaert AS, Jarvis SP (2007) Beneficial characteristics of mechanically functional amyloid fibrils evolutionarily preserved in natural adhesives. Nanotechnology 18:44010-44015

Mostaert AS, Higgins MJ, Fukuma T, Rindi F, Jarvis SP (2006) Nanoscale mechanical characterisation of amyloid fibrils discovered in a natural adhesive. J Biol Phys 32:393-401

Nakagawa H, Rhodes AR, Fitzpatrick TB, Hori Y (1984) Acid phosphatase in melanosome formation: a cytochemical study in normal human melanocytes. J Invest Dermatol 83:140-144

Ottaviani E, Franceschi C (1997) The invertebrate phagocytic immunocyte: clues to a common evolution of immune and neuroendocrine systems. Immunol Today 18:169-174

Ottaviani E, Capriglione T, Franceschi C (1995) Invertebrate and vertebrate immune cells express pro-opiomelanoortin (POMC) mRNA. Brain Behav Immun 9:1-8

Ottaviani E, Franchini A, Franceschi C (1997) Pro-opiomelanocortinderived peptides, cytokines and nitric oxide in immune responses and stress: an evolutionary approach. Int Rev Cytol 170:79-141

Ottaviani E, Malagoli D, Franceschi C (2007) Common evolutionary origin of the immune and neuroendocrine systems: from morphological and functional evidences to in silico approaches. Trends Immunol 28:497-502

Pearse AG (1972) Histochemistry: theoretical and applied, 3rd edn. Churchill Livingstone, Edinburgh

Pennacchio F, Strand MR (2006) Evolution of developmental strategies in parasitic Hymenoptera. Annu Rev Entomol 51:233-258

Pennacchio F, Malva C, Vinson SB (2001) Regulation of host endocrine system by the endophagous braconid Cardiochiles nigriceps and its polydnavirus. In: Edwards JP, Weaver RJ (eds) Endocrine interactions of insect parasites and phatogens. BIOS, Oxford, pp 123-132
Ratcliffe NA, Rowley AF, Fitzgerald SW, Rhodes CP (1985) Invertebrate immunity: basic concepts and recent advances. Int Rev Cytol 97:186-350

Remick DG (2005) Interleukine-8. Crit Care Med 33:466-467

Ribeiro C, Brehelin M (2006) Insect haemocytes: what type of cell is what? J Insect Physiol 52:417-429

Ruggeri A, Dell'Orbo C, Quacci D (1975) Electron microscopic visualization of proteoglycans with Alcian Blue. J Histochem 7:187-197

Salzet M (2000) Invertebrate molecular neuroimmune processes. Brain Process Rev 34:69-79

Salzet M, Salzet-Raveillon B, Cocquerelle C, Verger-Bocquet M, Sc P, Rialas CM, Laurent V, Stefano G (1997) Nitric oxide mediates hemolymph proopiomelanocortin processing. J Immunol 159:5400-5411

Scharrer B, Stefano GB (1994) Neuropeptides and autoregulatory immune processe. In: Scharrer B, Smith EM, Stefano GB (eds) Neuropeptides and immunoregulation. Springer, London New York, pp 1-13

Scharrer B, Paemen L, Smith EM, Hughes TK, Liu Y, Pope M, Stefano GB (1996) The presence and effects of mammalian signal molecules in immunocytes of the insect Leucophaea maderae. Cell Tissue Res 283:93-97

Schmidt O, Theopold U, Strand M (2001) Innate immunity and its evasion and suppression by hymenopteran endoparasitoids. BioEssays 23:344-351

Slominski A, Zbytek B, Szczesniewski A, Semak I, Kaminski J, Sweatman T, Wortsman J (2005) CRH stimulation of corticosteroids production in melanocytes is mediated by ACTH. Am J Physiol Endocrinol Metab 288:701-706

Smith EM, Hughes TK, Leung MK, Stefano GB (1991) The production and action of ACTH-related peptides in invertebrate hemocytes. Adv Neuroimmunol 1:7-16

Squier TC (2001) Oxidative stress and protein aggregation during biological aging. Exp Gerontol 36:1539-1550

Swerdlow RH, Khan SM (2004) A "mitochondrial cascade hypothesis" for sporadic Alzheimer's disease. Med Hypotheses 63:8-20

Verhaert P, Marivoet S, Vandesande F, De Loof A (1984) Localization of CRF immunoreactivity in the central nervous system of three vertebrate and one insect species. Cell Tissue Res 238:49-53

Wang DS, Dickson DW, Malter JS (2006) $\beta$-Amyloid degradation in Alzheimer's disease. J Biomed Biotechnol 2006:58406

Whitfield JB, Asgari S (2003) Virus or not? Phylogenetics of polydnaviruses and their wasp carriers. J Insect Physiol 49:397-405

Wolff K, Schreiner E (1971) Melanosomal acid phosphatase. Arch Dermatol Res 241:255-272

Zheng L, Roberg K, Jerhammar F, Marcusson J, Terman A (2006) Autophagy of amyloid beta-protein in differantiated neuroblastoma cells exposed to oxidative stress. Neurosci Lett 394:184-189

Zhu X, Perry G, Smith MA (2004) Two hits and you're out? A novel mechanistic hypothesis of Alzheimer disease. Lancet Neurol 3:219-226 